\title{
The Impact of Rules Changes on the 2012 Republican Presidential Primary Process
}

\author{
Joshua T. Putnam
}

Published online: 21 August 2012

(C) Springer Science+Business Media, LLC 2012

If there has been one consistent "law" of the presidential nomination process in the time since the McGovern-Fraser reforms fundamentally altered the way in which Americans nominate candidates for the two major parties starting in 1972 , it is that lessons are learned from one nomination cycle to the next. The 2012 nomination process was no different. What was witnessed over the first half of 2012 was in part-whether large or small-attributable to what happened in 2008. In other words, both the set up-in terms of the rules governing the delegate selection process - and the way in which the process played out were reactionary; the extension of a dynamic quadrennial process.

To see this in full contrast one must first look back at 2008. If the events of one cycle are in reaction to the immediately prior cycle, then what was it (or what was it that was wrong) about 2008 that laid the groundwork for what happened in 2012? It should be noted that the process of nominating a presidential candidate is a party function. The rules governing the election of delegates on the state level are the domain of, first, the national parties but then with some input from the state parties as well. If a problem is perceived to have arisen in the process, the remedy to that issue for the next iteration will find its nexus from within the national parties. Typically, it has been the Democratic Party in the post-reform era that has been the most active in tinkering with its presidential nomination rules; forming commissions every 4 year to refine the method of choosing the party's nominee. However, with no competitive race in 2012, the Democrats only slightly tweaked the rules the party utilized during the Obama-Clinton race in 2008.

\section{J. T. Putnam $(\triangle)$}

Department of Political Science, Davidson College,

102 North Main St.,

Davidson, NC 28036, USA

e-mail: joputnam@davidson.edu
It was, instead, the competitive Republican environment that proved the more hospitable to any form of system change. In fact, partly in coordination with the Democratic Party and partly in response to the longevity of and enthusiasm behind the 2008 Democratic nomination battle, the Republican National Committee took the unprecedented step of examining its 2012 delegate selection rules outside of the confines of the national convention (where the decisions for rules for the next cycle are typically made). The Republican Temporary Delegate Selection Committee saw the same problem in 2008 that its counterpart commission on the Democratic Party side saw: the process started too early and there were too many contests too early on the primary calendar during that cycle.

Iowa kicking the process off on January 3, 2008 placed, in the eyes of those within the national parties, a seemingly unnecessary burden on the candidates, campaigns and voters over the holiday season. Additionally, having over half of the country voting on the same date just a month later theoretically gave an advantage to either the frontrunner candidate - as measured by the polls and fundraising - or to an upstart candidate from outside of the party establishment who could win early and establish enough momentum to carry said candidate through the early series of contests. Though the parties view the latter as more problematic, the former has become progressively truer as the frontloading of primaries and caucuses has intensified in the time since reform. Still, the national parties - acting through their respective rules-making bodies - foresaw the potential for the retail politics both parties attempt to nurture through early contests in small states like Iowa and New Hampshire to be reduced or for the parties to lose even more control over the presidential nomination process.

To deal with the Iowa issue (starting too early), members of the rules making committees in both parties informally agreed that the starting point of the process should be 
pushed back into February. For both parties that meant Iowa, New Hampshire, Nevada and South Carolina-the so-called "carve out" states-holding February contests with all other states granted the ability to caucus or conduct primaries on the first Tuesday in March or thereafter.

In order to deal with the crowding problem - other states/ state parties positioning their contests early and close enough to the carve out states as to push them to even earlier than intended spots on the calendar - the DNC and RNC had different approaches. The Democrats opted to provide a carrot to states willing to shift back the dates of their primaries or caucuses. States with contests later than March got progressively larger "bonus" delegates tacked onto their delegations the later their respective contests were. A state with an April contest received a $10 \%$ boost, a May state garnered a $15 \%$ bump and a June state, a $20 \%$ increase. Additionally, as a new recommendation handed down from the Democratic Change Commission, the DNC also rewarded states that attempted to cluster their primaries or caucuses with neighboring states. The incentive there was also a boost in delegates (15\%), but states could also benefit from a series of regionally proximate states better able to attract candidates than if the state held a lone contest or a primary or caucus concurrent with a large number of regionally diverse contests. Together, both bonuses were intended to entice state-level decision makers to move or consider moving their state's contests to points later on the calendar.

The RNC, on the other hand, approached the crowding problem in a different manner. Embedded in the Republican rules were both carrots and sticks. Gone were the days when the Republicans introduced - but did not stick with-the bonus delegate concept. Instead, the RNC, on the recommendation of the Temporary Delegate Selection Committee, took the unprecedented step of restricting the freedom of deciding the method of delegate selection for early states while maintaining the state-level latitude to decide how national convention delegates would be chosen in later states. ${ }^{1}$ In practice, this meant that states with contests on or after April 1 could allocate delegates in anyway the state party deemed fit. During the 2012 cycle, the most common response to these rules changes in later states was to maintain the status quo. The path of least resistance was for state parties to simply keep the same delegate allocation rules used in 2008 and before.

For early states, however, the restrictions laid out in the augmented Rule 15 of the Rules of the Republican Party meant that there had to be some element of proportionality to the delegate allocation plan implemented by a pre-April 1

\footnotetext{
${ }^{1}$ The environment that existed for post-April 1 states in 2012 was the same environment that existed for all states in previous cycles. Put simply, states - all states - were free to determine how they would allocate national convention delegates. That same freedom was only afforded to post-April 1 states in 2012.
}

state. States could not, in other words, allocate all of their delegates to a statewide plurality winner. The mandate that came down from the RNC was not nearly as uniform as the restrictions on the Democratic side. The Democrats require a strict proportional allocation of all of the party's delegates. A candidate who receives $55 \%$ of the vote in a primary or caucus would be allocated approximately $55 \%$ of the state's total delegates. The Republican Party in its rules change took a broader view of the definition of "proportional". Again, any resultant delegate selection plan in a pre-April 1 state had to have an element of proportionality. The reality was that the RNC was prohibiting a strict, electoral collegestyle, winner-take-all allocation of delegates in that preApril 1 window. That was the stick. The carrot was that states wanting to avoid that penalty or desiring a shift to winner-take-all rules could move back to a later date to protect a winner-take-all method of allocation or the freedom to choose any method of allocation.

What did not happen in the commission and committee meetings that ultimately set the overall national party delegate selection rules for 2012 was anything to fix the Florida/ Michigan problem from 2008. The parties attempted in the ways described above to incentivize the movement of states to later dates, but did nothing to augment the penalties associated with rogue states; those states undeterred by penalties and not sufficiently enticed by the promise of additional delegates. That had the effect of undermining the efforts both parties had undertaken to back up the date of the first contest (the caucuses in Iowa) or to prevent the type of crowding that might force Iowa or any of the other carve-out states to earlier and non-compliant dates.

\section{Implementation of the Rules in the States \& Fallout from Penalties}

Heading into 2011, there were 20 states that had to make some change to either state election law or state party bylaws to alter the dates on which their primaries or caucuses were scheduled for 2012. By and large, the bipartisan coordinated calendar was effective in shifting most states back. The threat of reducing by half a non-compliant state's delegation was a seemingly sufficient penalty to keep most states in line. That both parties were on board with the changes meant that partisanship or negative partisan motivations behind primary date-setting had been largely removed from the decision-making calculus. It was not absent, but reduced with both national parties presenting a united front.

While the national parties presented a united front in terms of the adoption of a relatively uniform set of rules governing the presidential primary calendar, the method of sanction for breaking those rules continued to differ across 
parties and undermine the intent of the overall rules changes. Under the 2012 rules, both the DNC and RNC penalized a state in violation of the timing rules-when a state can schedule its nominating contest-half its delegation. Additionally, the Democratic Party rules sanctioned candidates who campaign in rogue states in an attempt to keep them from campaigning in those states. The Republican Party rules reduced a state delegation by half for a violation of either the timing rules or the aforementioned proportionality requirement, but did not have the authority to double penalize a state. The $50 \%$ delegate reduction could have been used in response to a violation of one rule but not both.

With the Democratic Party idle in 2012, primary calendar movement - or lack thereof - was more a function of the Republican Party rules than anything else. Most states were threatened enough by the potential loss of half a delegation to move back to a date that was compliant with national party rules or were deterred from moving up to a non-compliant date. Of the previously cited 20 states that had to shift back the dates on which their primaries or caucuses were held, 17 moved into compliance. The three that did not-Arizona, Florida and Michigan - forced the hands of the four carveout states, initially pushing each into January. ${ }^{2}$

In so doing, the three rogue states created three tiers of states on the primary calendar: 1) Carve-out states willing to break the rules in order to protect a calendar position codified in national party rules (i.e.: New Hampshire and South Carolina); 2) States willing to break the rules in order to be early but not necessarily earlier than the carve-out states (i.e.: Arizona, Florida and Michigan); and 3) States willing to follow the rules (i.e.: every state with a contest on or after the first Tuesday in March). That small group of rulesbreakers in the second tier wreaked havoc on the carefully constructed calendar the national parties had assembled, forcing a repeat of the January 3 start to primary season from the 2008 cycle. That tier of states not only rendered the parties' efforts to rein in the Iowa problem, but also reignited the Florida/Michigan problem that arose in 2008. The crux of that latter problem is that there is no one size fits all approach to effectively penalizing states in violation of

\footnotetext{
${ }^{2}$ The Nevada Republican Party originally moved the date of its precinct caucuses from February 18 to January 14 in response to the Florida Presidential Preference Primary Date Selection Committee decision to schedule the Florida primary for January 31 . That decision in Nevada severely curtailed the ability of the Iowa Republican Party and New Hampshire Secretary of State, Bill Gardner, to comply with respective state laws requiring a certain amount of time between each of the two earliest states' contests and any other similar contest. The move granted neither Iowa nor New Hampshire the space necessary to follow state law and still schedule the primary or caucus in the calendar year 2012. The resultant standoff between New Hampshire and Nevada culminated with the Nevada GOP moving the caucuses in the Silver state back to February 4, the Saturday following the Florida primary. That placed Nevada fifth instead of third in line-the rules-implied position - in the primary calendar shuffle.
}

delegate selection rules. What Alabama and Connecticut, for example, view as strong and effective penalties, Florida, Michigan and now Arizona do not. That second tier of states valued influence on the nomination race over potentially losing half of their delegates to the national convention. Conversely, the states that shifted back the dates on which their 2012 primaries and caucuses were held valued a full delegation over going early. Those states were willing to roll the dice, wagering that the Republican nomination race would still be competitive by the time the contest entered March and later points on the calendar.

Much of the talk in the press around the time the calendar was taking its final form revolved around the domino effect the Florida decision had on the first part of the primary calendar. Members of the Republican-controlled date selection committee in Florida, mindful of the impact the state had on the 2008 contest, were motivated to place the Sunshine state primary in a similarly decisive role in the 2012 Republican race. The pattern of movement exhibited by other states was just as instructive. Republican-controlled states - whether state governments or state parties - tended to move back less than Democratic-controlled states. The Republican states tended to shift back into March positions while more Democratic states occupied April and later dates when they moved. That created a calendar that was regionally and ideologically diverse at its outset, but one that was more southern and more conservative in March and more mid-Atlantic/northeastern and less conservative in April.

This was motivated by a confluence of factors. First of all, [compliant and] Republican-controlled states were deterred from holding February or earlier contests, but simultaneously wanted to impact the competitive Republican nomination race in 2012. March was as much of a gamble as decision makers in most of those states were willing to take. In the frontloaded era, earlier was and is better in terms of guaranteeing voters a voice in the presidential selection process. Over time however, occupying that early space on the calendar meant sharing any given date with enough other states to render that voice nearly mute. That reality, in concert with later states playing a role in the 2008 process, had a handful of states reconsidering the combination of an early but crowded primary or caucus date. In 2012 that left states with a desire to be early enough, but to also seek out a position that maximized the attention a state would receive from candidates and the media.

As alluded to above, though, this movement had a partisan element to it as well. Republican-controlled statesTennessee and Virginia, for example-were less likely to inch back too far on the calendar for fear of holding a contest outside of the window of decisiveness. Democratic-controlled states had a choice of whether to maintain the status quo or move back and take advantage of the late-contest delegate bonuses and/or the clustered- 
states bonuses. Several, like Massachusetts and Vermont, remained consistent with what state law had originally mandated in terms of the primary dates while other states, such as Connecticut, Delaware, New York and Rhode Island, opted to move their respective primaries back into late April time slots.

What did not seemingly motivate states in positioning their various delegate selection events for 2012 was the new addition to the Republican rules: the rule requiring states with contests prior to April 1 to have a proportional element to their delegate allocation. The change was viewed within the $\mathrm{RNC}$ as both a deterrent to states moving primaries and caucuses up, but also as a reward to states that moved back. However, states that shifted back to or maintained March dates, in most cases, did the bare minimum to comply with the strictures of the new rule, and states that selected dates later than April 1 merely maintained the delegate selection rules they had used in prior cycles; a nod to local custom. Counterintuitively, the only post-April 1 states that altered their delegate selection rules-Connecticut and New York -adopted slightly more proportional rules than what each had previously used. The consensus within the RNC was that states that voluntarily moved to dates in April and later would gravitate toward a more winner-take-all formula of delegate allocation. That was not the case in 2012.

\section{The Rules' Impact on the 2012 Republican Nomination Race}

That the Republican Party made seemingly significant delegate selection rules changes - and atypically, outside of the usual venue (the preceding convention) - was noteworthy, but in practice the Republican-specific rules had little influence over the nomination race that resulted in the winter and spring months of 2012. As was described above, most states that were required to move to later dates under the informally coordinated calendar structure both parties adopted, did, in fact, move back. Arizona, Florida, Michigan and a host of non-binding caucus states pushing into February only served to force an earlier-than-intended start to the process followed by a dead period throughout the middle and end of February.

At the outset of primary season, the fits and starts beginning opened the door to one candidate-presumably the nominal frontrunner, Mitt Romney-sweeping the early contests and effectively ending the race in a manner not inconsistent with the way in which a host of candidates in previous cycles had wrapped up nominations. Al Gore and George W. Bush in 2000 as well as John Kerry in 2004 were able to win early and often enough to signal to primary voters, if not opposing candidates, that the parties' rankand-file were lining up behind them. The voters did fall in line, but that may have been precipitated by the withdrawal of the remaining viable candidates from those respective races.

That pattern of early wins as a springboard to massive Super Tuesday victories has been what the frontloaded era, post-reform, increasingly had moved toward up until the 2008 cycle. The flirtation with primaries and caucuses scheduled in the year prior to the election in the lead up to 2008 coupled with an early February Super Tuesday that featured enough states to constitute well over half of the total number of delegates in both parties' competitive nomination races, forced some within not only the national parties but actors on the state level to reconsider the utility of such early contests.

The Romney campaign planned for the long haul but hoped for a quick win on the order of what Bush, Gore and Kerry were able to do following the turn of the century. Instead of that, Romney got something closer to, though not nearly like, the slower path Obama trod in winning the Democratic nomination 4 years earlier. Part of that slower build for Romney was a function of the early split of contests: Santorum winning Iowa, Romney winning New Hampshire, Gingrich winning South Carolina, Romney winning Florida, Maine and Nevada and Santorum winning Colorado and Minnesota in the contests prior to the dead period in February.

The early calendar split decision worked in conjunction with a couple of other factors to draw out the Republican nomination contest. One was rules-based and the other was more psychological in nature. Obviously, the 2012 presidential primary calendar was much more evenly dispersed - in terms of the contests - than was the case with the 2008 calendar. January contests in 2012 did not feed into a de facto national primary on the first Tuesday in February as in 2008. By its nature, that shift fundamentally altered the way in which delegates would be accumulated by candidates from contest to contest. The earliest point that a candidate could have won the requisite number of pledged/bound delegates to clinch the nomination moved back from February 5 during the 2008 cycle to March 20 in 2012.

Logically, it may also be assumed that the new proportionality requirement would also slow down the pace of delegate accrual. If, after all, states are changing from more winner-take-all rules to rules that have an increased level of proportional allocation embedded in them, then the seemingly obvious conclusion would be that the process would be slower. It was not, and that was due in large part to where states were located and the percentage of evangelicals in a given state. Southern and/or more highly evangelical states were more likely to split their support among Mitt Romney, Newt Gingrich and Rick Santorum with the latter two candidates usually outpacing Romney in the resulting delegate counts. However, the shift to slightly more proportional 
rules kept Romney closer than the former Massachusetts governor otherwise would have been in past years. Without the proportionality requirement and under the 2008 rules, Rick Santorum would have gained not only victories but a greater delegate advantage coming out of some of the midMarch southern contests; pulling closer to Romney and drawing out the process even further than was actually the case in 2012.

While the impact of the proportionality rule for states with contests prior to April 1 paled in comparison to the calendar changes overall, the new rule did factor into the greater psychology - and resultant candidate/campaign strategy — of the 2012 primaries. What the proportionality requirement along with the influx of Super PAC money into a presidential nomination context collectively did was to alter the approach of candidates - particularly those who were attempting to break Mitt Romney's seemingly tenuous hold on the frontrunner mantle. Both served as strategic lifelines. Though the reality was that the delegate accumulation was not fundamentally different in 2012 than it had been in previous cycles, the candidates were behaving as if it was. ${ }^{3}$ The change in rules seemingly, though not really, opened the door to candidates competing not for contest wins alone but for delegates in more proportional states. Similarly, Super PAC money allowed candidates who had one or more big-money donors to keep a campaign alive even if small donors had largely disappeared or stopped contributing to the campaigns. Those two lifelines kept the Santorum and Gingrich candidacies afloat financially and rife with messages of the next battleground for delegatesno matter how far-fetched.

The 2012 cycle was marked by a host of on-the-surface significant rules changes to both parties' sets of delegate selection rules. As usual, those rules had a hand in affecting the course of the nomination race, but not necessarily in the ways that the parties may have intended. The spreading out of the calendar of contests played a larger role than anything else. This was particularly true relative to the expectations versus reality of the newly instituted proportionality requirement on the Republican side. The intention was for that rule to draw out the point at which the Republican nomination was clinched and as a result bring additional states into the window of decisiveness. That goal was not realized through the proportionality rule but rather by spreading out the dates of the various primaries and caucuses. The result was that even though it took a different route to get there- the frontrunner won the Republican nomination.

Josh Putnam is a visiting assistant professor of political science at Davidson College who blogs at Frontloading HQ, which has garnered national media attention in the lead up to and during the 2012 presidential election cycle.

\footnotetext{
3 There were only six strictly winner-take-all states in the Republican process in 2012, a number just four less than the number of states with similar rules in 2008 . 